$>$ pressure. Human population growth, farming and the construction of dams and highways threaten panda reserves across China. Programmes to return captive pandas to the wild are a distraction from what really matters: protecting wild pandas, which are endangered not by their biology but by the loss and fragmentation of their habitat.

Nicholls acknowledges the enormous challenge China faces to balance economic development and conservation. He is right to point out that the country has made extraordinary leaps: it has added another 60 panda reserves covering more than $70 \%$ of suitable habitat; introduced tougher enforcement of blanket logging bans within nature reserves; and invested tens of billions of dollars in a series of policies, such as the Natural Forest Protection Programme and the Sloping Land Conversion Programme, to encourage forest protection and restoration.

Yet Nicholls does not sufficiently explore the substantial gap between these well-intentioned conservation plans and their incomplete implementation in practice, a problem that plagues many areas of development in the country. Despite China's pledge to protect the environment, economic development frequently takes precedence at the provincial level. Consequently, panda habitats are often destroyed or fragmented to make way for major infrastructure projects such as dams and highways.

Tourism is also a threat. For example, Jiuzhaigou, part of the pristine Sichuan Giant Panda Sanctuary - a World Heritage Site - is visited by millions of tourists each year. Nicholls notes that even when ecotourism is deliberately introduced to provide local people with a livelihood that is not damaging to nature reserves, economic benefits often go to investors based outside the community. Hotel and restaurant owners tend to import skilled workers rather than train locals. Hence, he points out, local people often continue to chop down trees or convert forests into farmland.

Through this engaging tale of the panda's plight, Nicholls highlights how conservation pressures are often pitched against economic ones. At the recent United Nations Convention on Biological Diversity summit in Nagoya, Japan, there was broad acknowledgement that radical steps to reform economic and social development are necessary to protect natural resources. Such a strategy could be the best hope for the giant panda and other species that face extinction.

Jane Qiu writes for Nature from Beijing.

\section{Catching up with the Sun}

\section{Douglas Gough enjoys a wide-ranging tour of the many influences of our nearest star.}

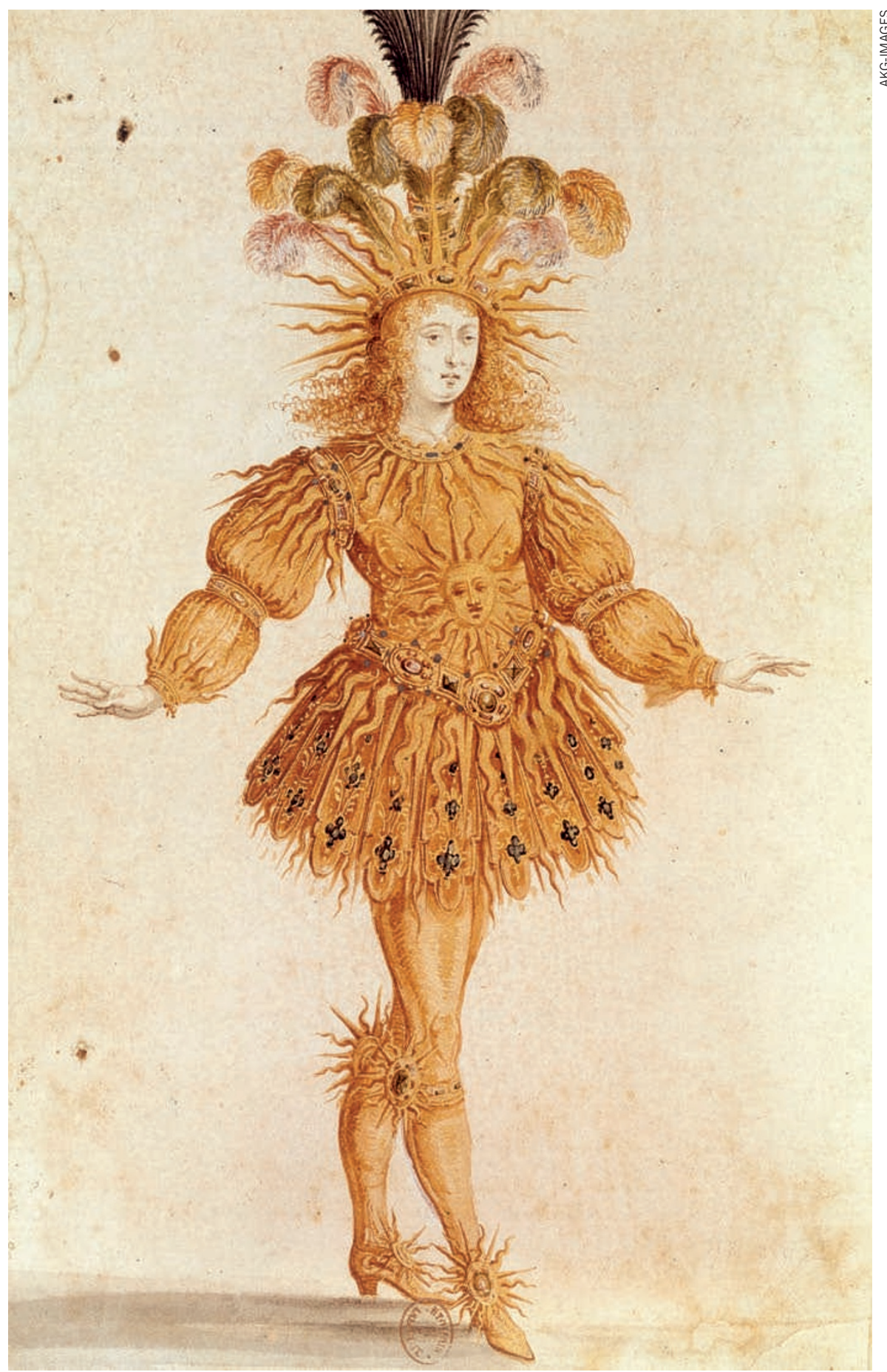

Louis XIV of France named himself the Sun King to bolster his authority. 
$\mathrm{T}$ o humankind, the Sun is the most important body in the Universe. It has been deified and associated with fecundity and eroticism, it pervades literature, art and film, and it influences our daily moods. Studies of the Sun motivated revolutionary changes in scientific thought in the twentieth century - including quantum mechanics and general relativity - and today its workings still constitute a most important branch of astronomy and astrophysics. To write yet another work about our nearest star is a formidable challenge that author Richard

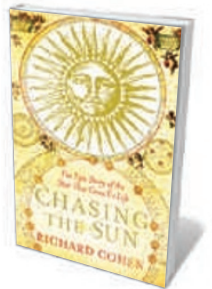

Chasing the Sun: The Epic Story of the Star That Gives Us Life RICHARD COHEN Simon \& Schuster/ Random House: 2010. $704 \mathrm{pp} / 608 \mathrm{pp}$. $£ 30 / \$ 35$ Cohen takes up with aplomb. Chasing the Sun paints a fascinating and far-reaching scene that incorporates nearly all aspects of solar phenomena.

Cohen touches on a range of histories of Sun-related myths, religions, superstitions and traditions. From Babylon, Egypt and Greece to China, Persia, India, Peru, Arabia and Japan, ancient cultures established observatories to chart the motions of the Sun, the Moon, planets and stars. Because the annual shift of the Sun's path across the sky is pertinent to the survival of agrarian societies, these cultures developed calendars to determine when crops should be sown.

The Sun was a god to many civilizations, and rulers often derived their authority by asserting that they were descended from it. Cohen describes the influence of the Sun on architecture, art, music, literature, poetry and even politics. He discusses how our understanding of the physical nature of the Sun has developed, and, to a lesser degree, how that knowledge has advanced our understanding of physics.

The narrative is liberally sprinkled with personal anecdotes, which is largely what makes the book so enjoyable. Cohen describes how, early in the morning of the summer solstice of 2005 , he ascended

\section{"Many dates} owe their origins to the Sun's movements even the start of the UK tax year."

Mount Fuji in Japan

to see the sunrise with the words "You run and you run to catch up with the Sun" from Pink Floyd's song Time running through his ears. At the summit, he bathed in the colours of the rapidly changing skyline - indigo, purple, ochre - and, when the full glare of the Sun struck home, he

\section{Books in brief}

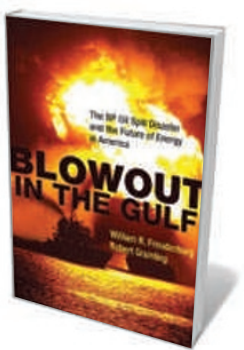

Blowout in the Gulf: The BP Oil Spill Disaster and the Future of Energy in America

William Freudenburg and Robert Gramling THE MIT PRESS

240 pp. \$18.95 (2010)

Environmental scientist William Freudenburg and sociologist Robert Gramling set the recent Gulf of Mexico oil spill in the broader context of energy policy. After examining decisions made during attempts to stifle the gushing well, they point the finger at the oil industry for cutting regulatory corners and pocketing the proceeds. In future, greater emphasis should be put on prevention, and risk assessments should include human as well as hardware foibles, they argue.

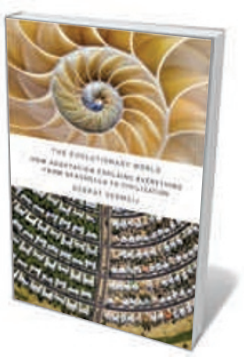

The Evolutionary World: How Adaptation Explains Everything from Seashells to Civilization

Geerat J. Vermeij THOMAs DUNNE Books 336 pp. \$27.99 (2010)

In his far-ranging book, geologist Geerat Vermeij stretches the implications of evolution to all aspects of society, from religion to morality. With a focus on adaptation and using examples from ecosystems around the world, he explains how natural selection has influenced human civilization and underpins our economic system, the development of communities and our attitudes to risk. Only by understanding these forces, he argues, can we prepare for the challenges that lie ahead.

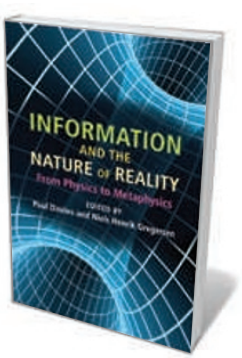

Information and the Nature of Reality: From Physics to Metaphysics

Edited by Paul Davies and Niels Henrik Gregersen

CAMBRIDGE UNIVERSITY PRESS 398 pp. $\$ 30$ (2010)

Information, rather than mass and energy, is coming to be seen as the fundamental currency of the Universe. Eminent scientists, philosophers and theologians come together in this anthology to chart this shift in thinking. After describing the historical development of theories of quantum, biological and digital information, they contrast biological and physical approaches to information and examine the philosophical and ethical implications of the concept.

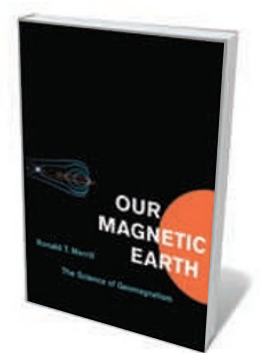

Our Magnetic Earth: The Science of Geomagnetism Ronald T. Merrill UNIVERSITY OF CHICAGO PRESS 272 pp. \$25 (2010) Earth's magnetic field is a valuable tool, influencing everything from compass settings to the migration of geese. It lays down in rocks a forensic record of the spreading of ocean floors, plate tectonics and past climate. It also protects our planet by deflecting damaging cosmic rays, and is sensed by organisms from bacteria to mammals. In his primer that is peppered with anecdotes, geophysicist Ronald Merrill explains why geomagnetism is central to Earth science and discusses how it could offer solutions to some of the biggest questions about our planet's future.

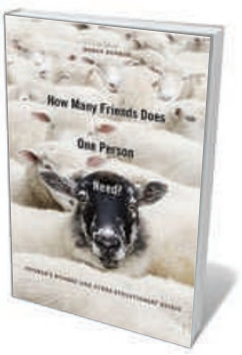

How Many Friends Does One Person Need? Dunbar's Number and Other Evolutionary Quirks

Robin Dunbar HARVARD UNIVERSITY PRESS 312 pp. \$27.95 (2010)

From our love of jokes to our degree of belief in religion, anthropologist Robin Dunbar seeks to explain why people behave as they do. Describing groundbreaking experiments that reveal how evolutionary biology underpins our behaviour, he asks why we laugh, why we should be suspicious of someone who has more than 150 friends on Facebook and why Barack Obama's 2008 US election victory was a foregone conclusion. 
understood why we say something 'dawns' on us. The book is also peppered with gems of information, such as the origins of the expressions high noon, high seas and plain sailing.

Much is said about time-keeping, and how many dates owe their origins to the Sun's movements: pagan festivals, Christian festivals, even the start of the UK tax year on 6 April. Cohen also goes into the dangers of sunlight; for example, he relates how, after the 1999 solar eclipse in England, doctors in a London hospital reported

$\checkmark$ NATURE.COM

For a review of discoveries from solar eclipses, see: go.nature.com/eozc5b that they could pinpoint the precise phase at which a patient had stared at the Sun from the shape of the 'sickle' damage to his or her retina.

This book is no stolid scholarly treatise. Cohen is mainly a storyteller, who, after more than seven years of research, has amassed a prodigious amount of information and organized it into an entertaining narrative. However, in not wanting to detract from the main point of his tale, he occasionally oversimplifies matters - especially those scientific ones for which veracity is sometimes left behind. For example, at the start of the book the casual reader might be led falsely to believe that the Sun is now contracting, later to fade into a red giant. This is contradicted

"The Sun did. contract from

the gas and dust of the

interstellar medium, but that tookjust 10 million years." nearly 600 pages later by a paragraph offering a more accurate view. The Sun did initially contract from the gas and dust of the interstellar medium, but that took just 10 million years. Since then and for almost all of its existence - some 4.6 billion years so far - it has been expanding, and will continue to do so at a steadily accelerating pace for nearly 6 billion years more. It will then expand rapidly into a highly luminous red giant, albeit with a lower surface temperature, before finally condensing to a white dwarf.

Despite shortcomings such as these, Chasing the Sun is a marvellous read. -

Douglas Gough is a Leverhulme Emeritus Fellow at the Institute of Astronomy, and professor emeritus of theoretical astrophysics in the University of Cambridge, Madingley Road, Cambridge CB3 OHA, UK. e-mail:douglas@ast.cam.ac.uk

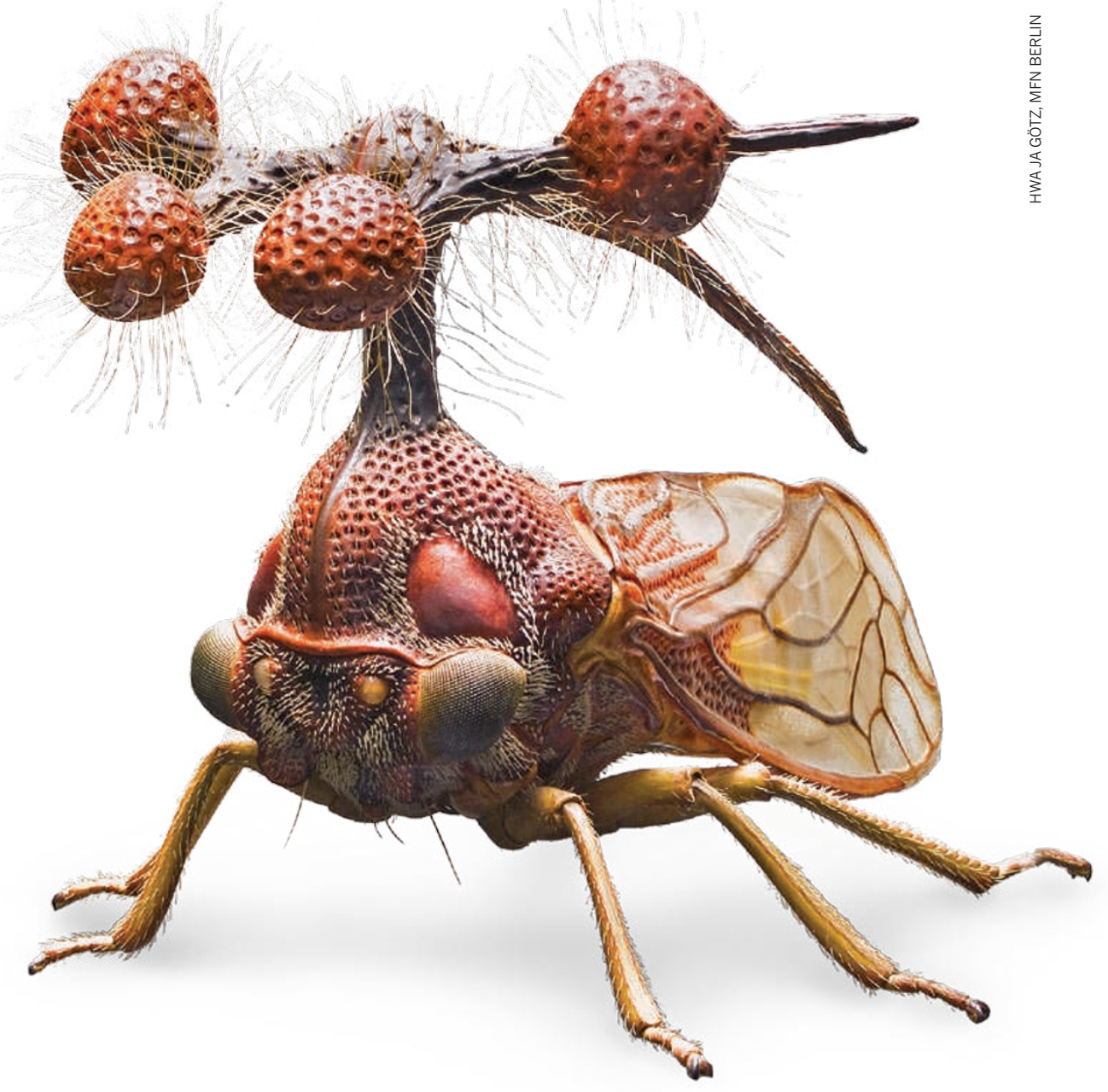

SCULPTURE

Terrible wonder

\section{Alfred Keller's fastidious models of insects highlight his skill as an observer and a sculptor, finds Martin Kemp.}

$\mathrm{V}$

enturing upstairs in Berlin's Museum für Gegenwart (Museum for Contemporary Art), we enter a darkened space inhabited by alien creatures, eerily spotlit in glass cases.

The specimens in the exhibition, Die Sammlungen (The Collections), exude an air of menace. As we look more carefully, as familiar insects, most obviously $\mathrm{Musca}$ domestica, the common housefly, and Pulex irritans, the flea, immortalized in Robert Hooke's Micrographia of 1665. The models, enlarged by a factor of 100, recall Hooke's comment about the terrible wonder of such magnified insects. He described the flea he viewed down his microscope as "adorn'd with a curiously polish'd suit of sable Armour, neatly jointed, and beset with multitudes we begin to recognize some of the monsters
Die Sammlungen (The Collections) Hamburger Bahnhof Museum für

Gegenwart, Berlin. Until 6 February 2011 as bizarre a creature as we might ever see. It looks like a cartoon beetle with some ultrasensitive receiving device of spheres and tendrils mounted on a short mast protruding from its back. It is in fact Bocydium globulare, the most extravagant of the leaf hoppers (pictured). The hollow globes, like the remarkable excrescences exhibited by other leaf hoppers, probably deter predators.

This model is by the brilliant sculptor, Alfred Keller (1902-55). Keller was trained as a kunstschmied, an 'art blacksmith'. From 1930 until his early death he was employed 